\title{
The use of temperature, stable isotopes and water quality to determine the pattern and spatial extent of groundwater flow: Nagaoka area, Japan
}

Published online: 2 August 2005

(C) Springer-Verlag 2005

Groundwater flow system $\cdot$ Tracers $\cdot$ Shinano River . Nagaoka, Japan

\section{Hydrogeology Journal 12(5):563-575}

It has come to the attention of the Editors that an article appearing nearly one year ago in Hydrogeology Journal is essentially the same article that was previously published in Ground Water. While this may have been an unintentional case of dual publication, the first author made the following statement in the letter that accompanied his initial submittal of 20 August 2002: "I would like also to state that this manuscript has not previously published [sic] and is not and will not be submitted for publication elsewhere while in review for Hydrogeology Journal. . . "In fact, the article was submitted to Ground Water two months earlier and was published in Ground Water several months before it appeared in Hydrogeology Journal. It was simultaneously in review for publication in both journals and was accepted in Hydrogeology Journal only after it had been published in Ground Water. The full references, submittal/acceptance history, and abstracts and of each article are reproduced below. Although there are some differences in conclusions and some additional material is presented in Hydrogeology Journal article, the articles present substantially the same

The online version of the original article can be found at http://dx.doi.org/10.1007/s10040-004-0368-7

\footnotetext{
Z. E. Salem $(\bowtie)$

Geology Department, Faculty of Science, Tanta University, 31527 Tanta, Egypt

e-mail: zenhoms@hotmail.com

Y. Sakura

Department of Earth Science, Chiba University, 263-8522 Chiba, Japan

M. A. M. Aslam

Graduate School of Science and Technology, Chiba University, 263-8522 Chiba, Japan
}

material. Two minor references are made to the Ground Water article in the Hydrogeology Journal article, but these do not indicate that the preponderance of the Hydrogeology Journal article is reproduced from the former version.

We apologize to the National Ground Water Association of the USA, owners of the copyright on the earlier article and would additionally like to give specific credit to the earlier publication for the following items:

- Figures 1, 2, 5, 7ab, 9, and 10 in the Hydrogeology Journal article are reproduced from Figures 1, 2, 3, 5, 10 and 11 in the Ground Water article.

- Table 1 from the earlier article is reproduced in the Hydrogeology Journal article.

Salem ZE, Taniguchi M, and Sakura Y (2004) Use of Temperature Profiles and Stable Isotopes to Trace Flow Lines: Nagaoka Area, Japan. Ground Water 42(1): 83-91

Received: 2 June 2002 Accepted: 7 March 2003

Appeared in January-February 2004 issue of Ground Water

Abstract In this study, we use borehole temperature data and stable isotopes to delineate the flow system and estimate the effect of urbanization in the Nagaoka area of Japan. Temperature profiles were measured four times in observation wells during the period 2000-2001 and compared with those measured in the same wells during the period 1977-1983 (Taniguchi 1986). Water was sampled in both observation and pumping wells during the same period. The temporal and spatial variability in temperature indicate clearly the effect of urban warming and heavy pumping on the ground water system. Urban warming caused higher temperatures recently as compared to the older values, and pumping caused induced recharge from the river to the ground water. The stable isotope data show the ground water flow system is divided into shallow, intermediate, and deep systems, and that land use and infiltration rate are affecting the shallow flow system.

Salem ZE, Sakura Y, and Aslam MAM (2004) The use of temperature, stable isotopes and water quality to determine the pattern and spatial extent of groundwater flow: Nagaoka area, Japan. 
Hydrogeology Journal 12(5):563-575

Received: 20 August 2002 Accepted: 29 June 2004 Appeared in October 2004 issue of Hydrogeology Journal

Abstract The purpose of this study was to trace the groundwater flow system in the Nagaoka area using subsurface temperature distribution, stable isotopes and water quality. Temperature-depth profiles were measured four times in observation wells during the period 2000-2002. Water was sampled from both observation and pumping wells during the same period. A combination of tracers was used to conceptualize the groundwater flow system. The flow system appears to be divided into shallow, intermediate and deep systems. It is clear that land use, pumping and the infiltration rate are affecting the shallow flow system. 